\title{
Ag Nanoparticle-Decorated Mesoporous Silica as a Dual-Mode Raman Sensing Platform for Detection of Volatile Organic Compounds
}

Maofeng Zhang, ${ }^{* a}$ Yongkai Liu, ${ }^{\mathrm{b}}$ Pengde Jia,${ }^{\mathrm{c}}$ Yingchao Feng, ${ }^{\mathrm{a}}$ Shuo Fu, ${ }^{\mathrm{b}}$ Jian Yang, ${ }^{\mathrm{b}}$ Liangzhong Xiong,

${ }^{\mathrm{d}}$ Fengmei Su, ${ }^{\mathrm{e}}$ Yucheng Wu ${ }^{\mathrm{b}}$, Youju Huang, ${ }^{* \mathrm{c}}$

a School of Chemistry and Chemical Engineering, Hefei University of Technology, 193 Tunxi Road, Hefei, 230009, China

b School of Materials Science and Engineering, Hefei University of Technology, 193 Tunxi Road, Hefei, 230009, China

c College of Materials, Chemistry and Chemical Engineering, Hangzhou Normal University, Hangzhou 311121, China

d Bozhou New Health Technology Co., Ltd., Modern Chinese Medicine industry entrepreneurial base, Block B, Yaowang Road, Bozhou, 236800, China

e National Engineering Research Centre for Advanced Polymer Processing Technology Key Laboratory of Materials Processing and Mold Ministry of Education, Zhengzhou University, Zhengzhou 450002, China

*Corresponding Authors: E-mail: mfzhang@hfut.edu.cn and yjhuang@hznu.edu.cn. 
(a)

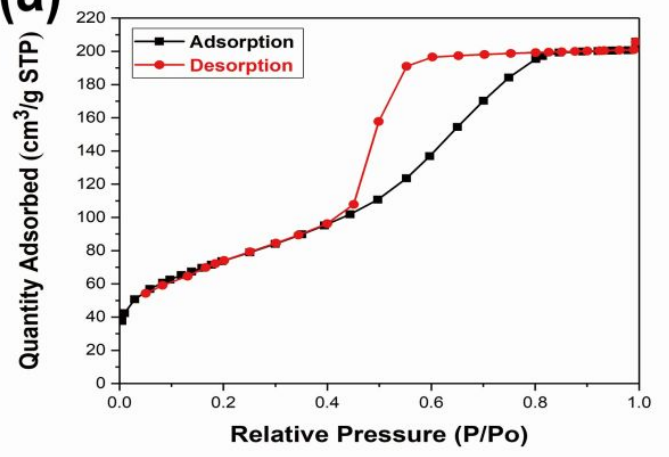

(c)

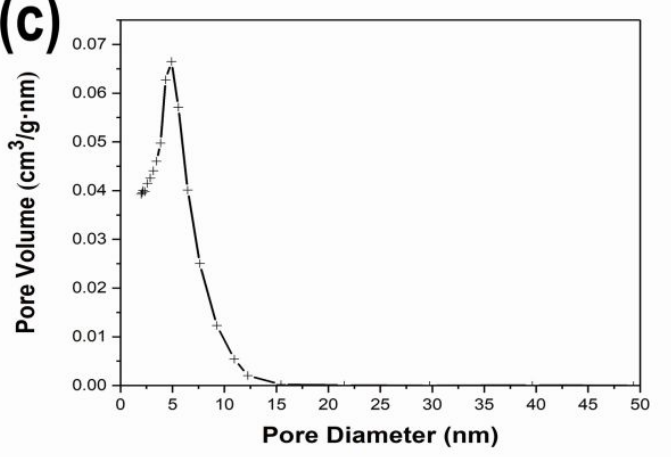

(b)

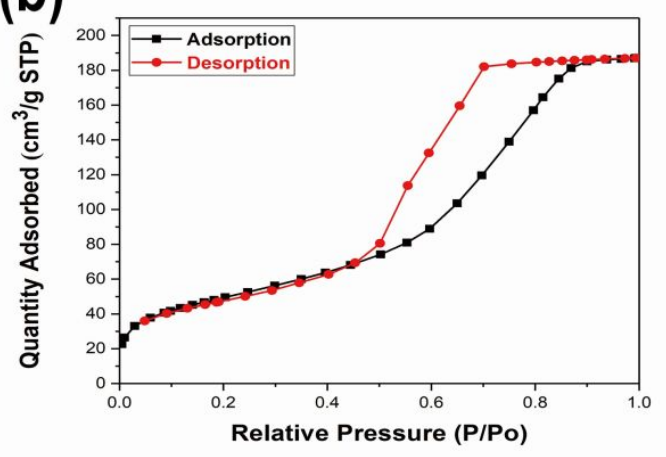

(d)

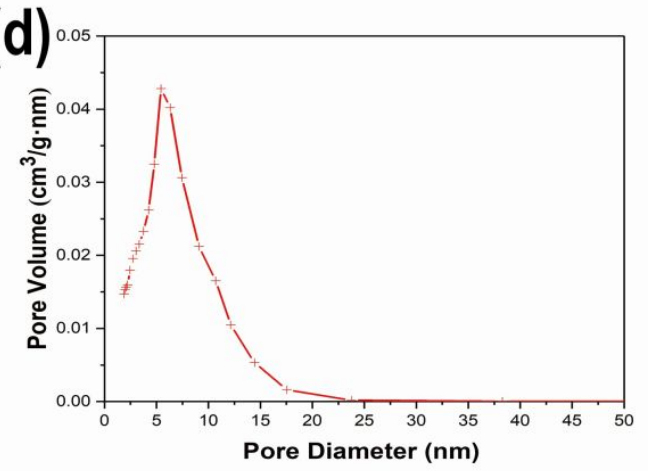

Figure S1. Nitrogen sorption isotherms of (a) $\mathrm{SiO}_{2}$ substrate and (b) $\mathrm{SiO}_{2}-\mathrm{Ag}$ substrate. Pore size distribution of (c) $\mathrm{SiO}_{2}$ substrate and (d) $\mathrm{SiO}_{2}-\mathrm{Ag}$ substrate. 


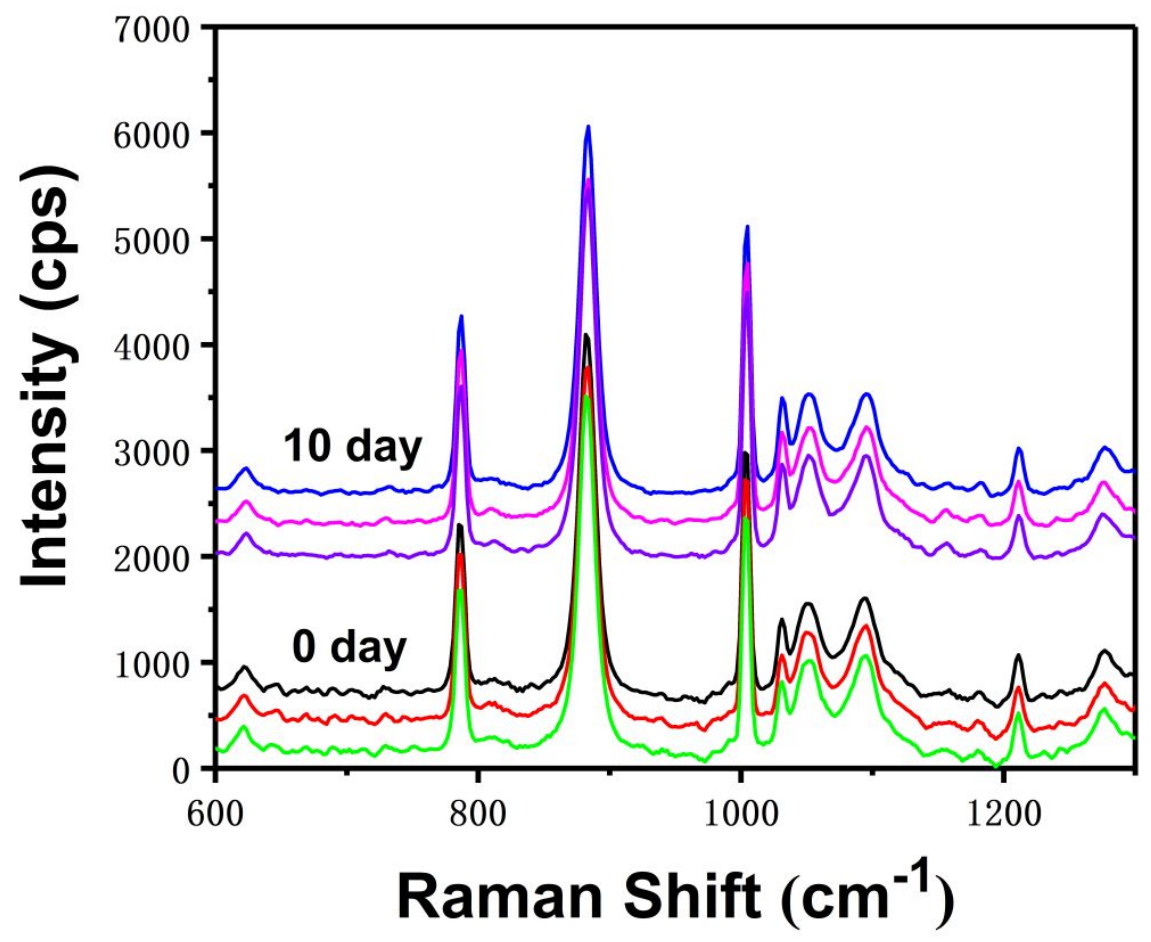

Figure S2. Raman spectra of freshly prepared samples and those stored for 10 days.

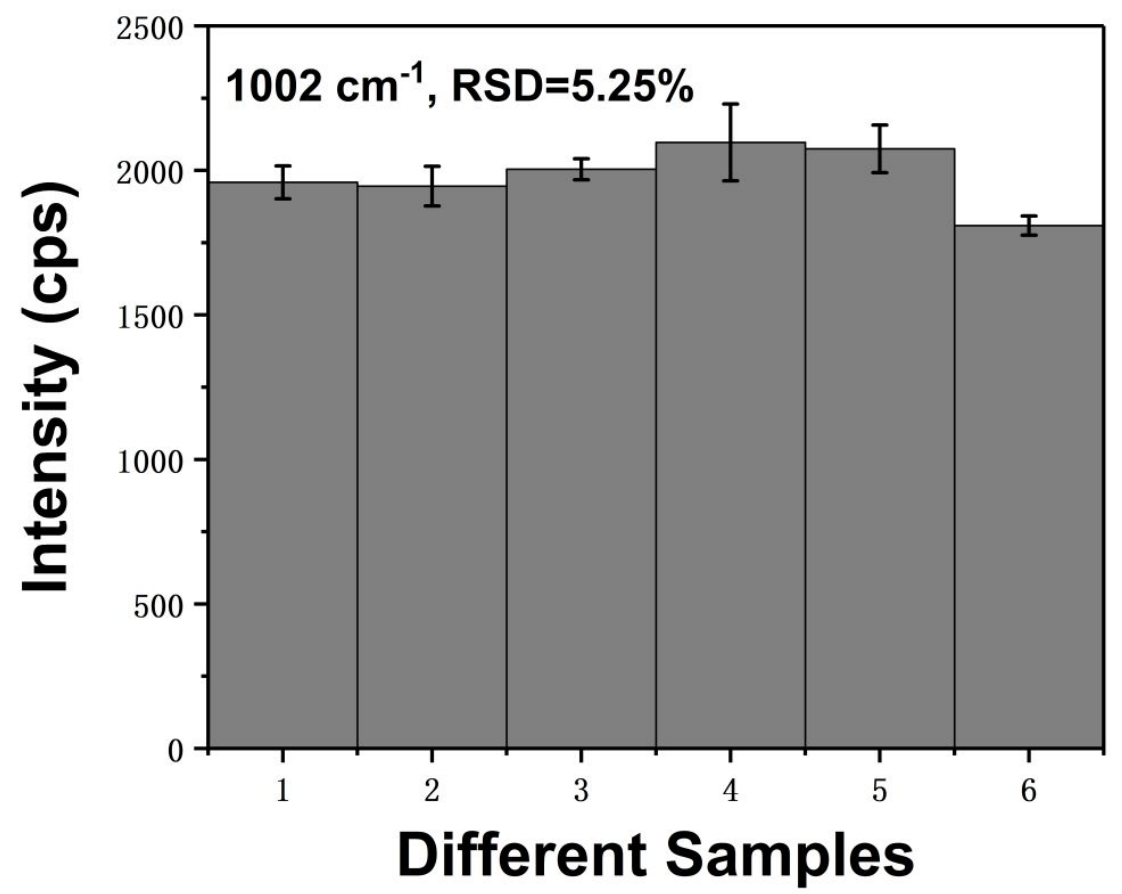

Figure S3. The Raman intensity RSD value of inter-substrate variation obtained at $1002 \mathrm{~cm}^{-1}$ peak. 


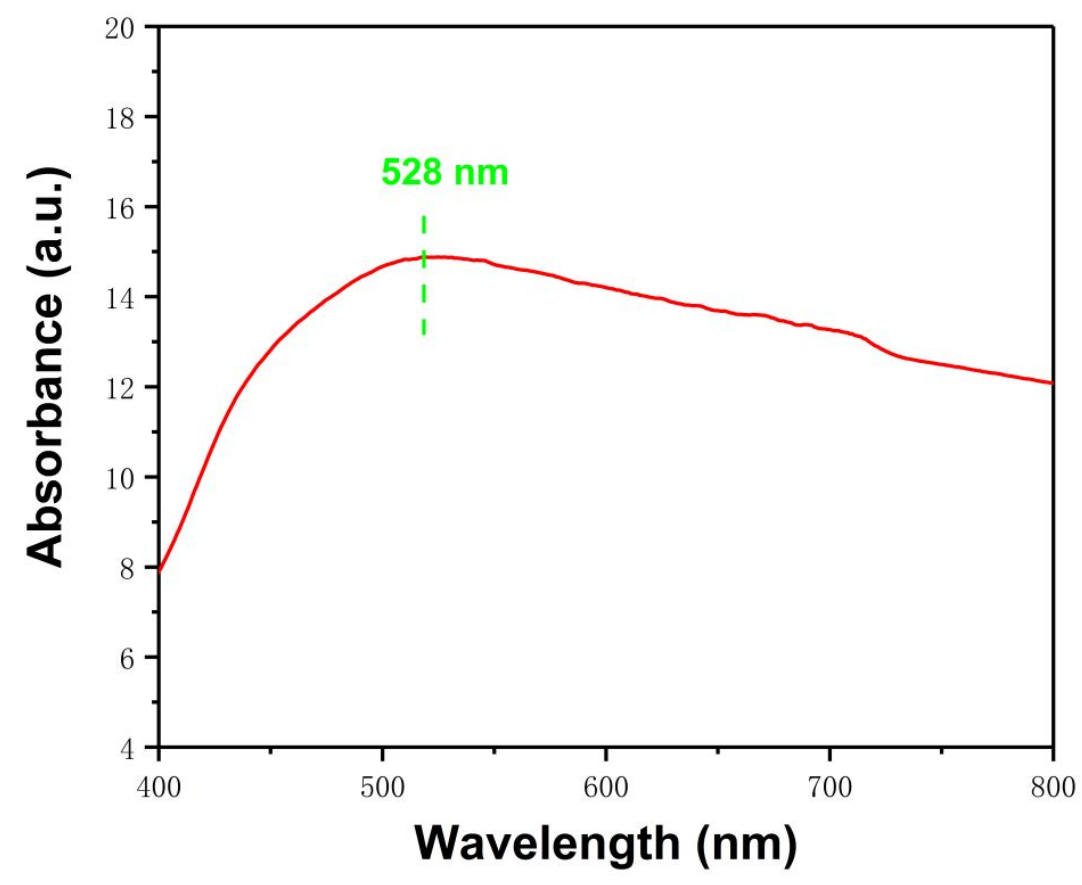

Figure S4. UV-Vis absorbance spectra of $\mathrm{SiO}_{2}-\mathrm{Ag}$ substrate.

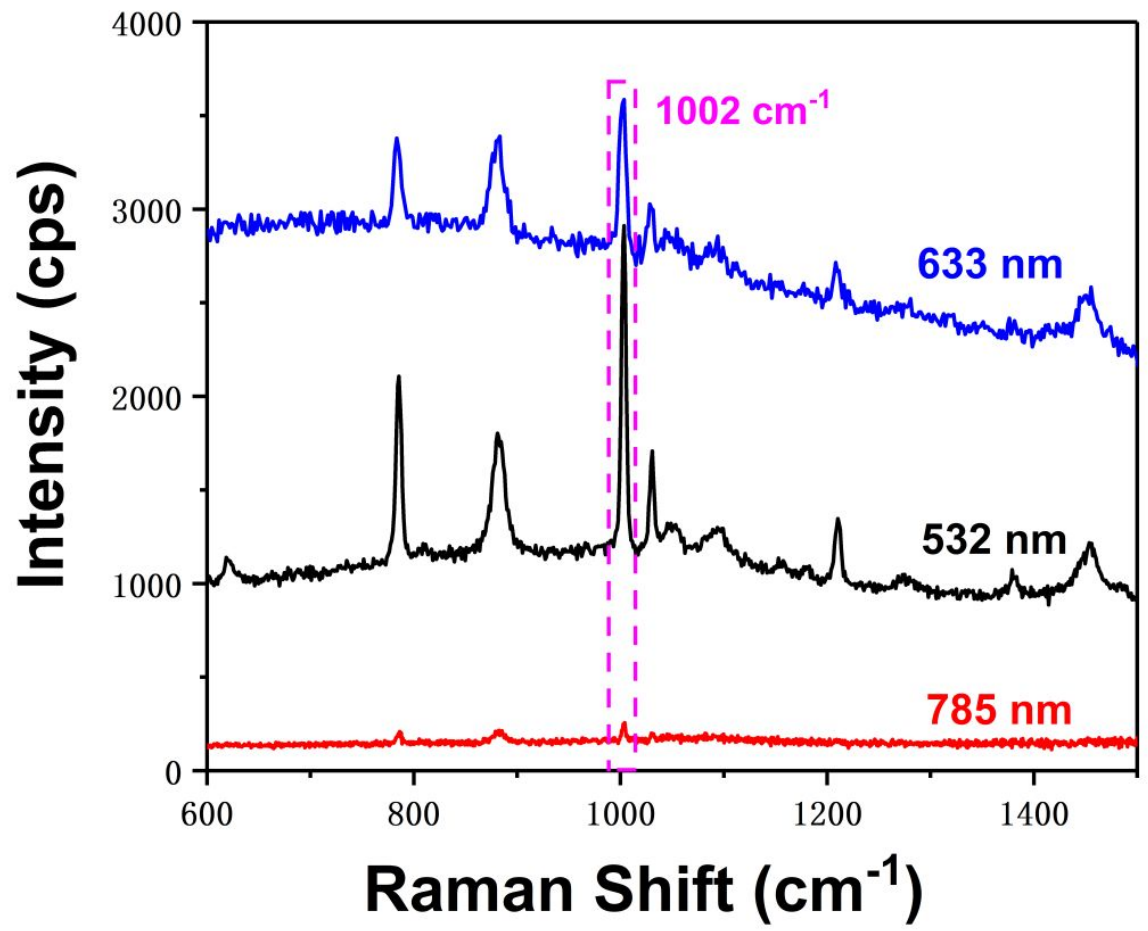

Figure S5. Relationship between Raman intensity and laser wavelengths. 


\section{Calculation of vapor concentration from liquid reservoir}

According to Raoul's law, by changing the molar fraction of the target molecular liquid in the liquid mixture, the atmosphere of the target molecular gas with different concentrations can be obtained. The specific calculation formula is as follows:

$$
C=\frac{N_{1}}{N} \times 10^{6}
$$

Where $N_{1}$ and $N$ is the number of moles of target gas and total number of gas molecules in the closed Raman cell respectively, $C$ is the concentration of component used in ppm.

According to raoult's law, the partial pressure of the components in the ideal mixture is equal to the molar fraction of the components in the solution. In this experiment, decane with low vapor pressure was used as an independent group to prepare the mixture. By calculating the vapor pressure of the target gas in the mixture with decane as solvent, the concentration of the gas was obtained. The atmosphere of target gas with different concentration can be obtained by changing the molar ratio of decane/target gas pure solution.

Take toluene as an example. At temperature $298 \mathrm{~K}$, the vapor pressure of toluene and decane is $3760 \mathrm{~Pa}$ and 190 $\mathrm{Pa}$ respectively. By changing the mole ratio of decane/toluene, different concentration of toluene vapor can be obtained. The following table is the toluene gas concentration corresponding to different mixtures.

Table S1. The toluene gas concentration corresponding to different mixtures.

\begin{tabular}{|l|c|c|c|c|c|c|c|}
\hline $\begin{array}{l}\text { The volume ratio of } \\
\text { toluene to decane }\end{array}$ & $1: 2$ & $1: 4$ & $1: 8$ & $1: 28$ & $1: 90$ & $1: 400$ & $1: 1000$ \\
\hline $\begin{array}{l}\text { Concentration of } \\
\text { toluene (ppm) }\end{array}$ & 17424 & 11516 & 6594 & 2229 & 713 & 169 & 68 \\
\hline
\end{tabular}

For example, toluene and decane solutions with a volume ratio of 1:1000 were mixed to obtain toluene gas at a concentration of $68 \mathrm{ppm}$. Also given that the density of toluene and decane is $0.8669 \mathrm{~g} / \mathrm{ml}$ and $0.7300 \mathrm{~g} / \mathrm{ml}$ respectively.

$$
n=\frac{V_{1} \rho_{1} / M_{1}}{V_{1} \rho_{1} / M_{1}+V_{2} \rho_{2} / M_{2}}=\frac{1 \times 0.8669 / 92.14}{1 \times 0.8669 / 92.14+1000 \times 0.73 / 142.29}=1.831 \times 10^{-3}
$$

Where $V$ is the volume of component used in $\mathrm{ml}, \rho$ is the density in $\mathrm{g} / \mathrm{ml}$ and $M$ is the molecular weight in $\mathrm{g} / \mathrm{mol}$. Component 1 represents toluene while component 2 represents decane. $n$ is the molar ratio of target gas.

$$
C=\frac{n P_{1}}{n P_{1}+(1-n) P_{2}} \times 10^{6}=\frac{1.831 \times 10^{-3} \times 3760}{1.831 \times 10^{-3} \times 3760+\left(1-1.831 \times 10^{-3}\right) \times 190+101325} \times 10^{6}=68 \mathrm{ppm}
$$

Where $P$ is the the vapor pressure of component used in $\mathrm{Pa}$.

Table S2. The benzene gas concentration corresponding to different mixtures.

\begin{tabular}{|c|c|c|c|c|c|c|c|c|}
\hline $\begin{array}{c}\text { The volume ratio of } \\
\text { benzene to decane }\end{array}$ & $1: 2$ & $1: 4$ & $1: 8$ & $1: 28$ & $1: 90$ & $1: 400$ & $1: 1000$ & $1: 5000$ \\
\hline $\begin{array}{c}\text { Concentration of } \\
\text { benzene (ppm) }\end{array}$ & 62304 & 43018 & 26569 & 9125 & 3006 & 691 & 277 & 56 \\
\hline
\end{tabular}


Table S3. The acetone gas concentration corresponding to different mixtures.

\begin{tabular}{|c|c|c|c|c|c|c|}
\hline $\begin{array}{c}\text { The volume ratio of } \\
\text { acetone to decane }\end{array}$ & $1: 90$ & $1: 200$ & $1: 300$ & $1: 400$ & $1: 1000$ & $1: 5000$ \\
\hline $\begin{array}{c}\text { Concentration of } \\
\text { acetone }(\mathrm{ppm})\end{array}$ & 8600 & 3951 & 2649 & 1992 & 801 & 161 \\
\hline
\end{tabular}

Table S4. The chloroform gas concentration corresponding to different mixtures.

\begin{tabular}{|c|c|c|c|c|c|c|}
\hline $\begin{array}{c}\text { The volume ratio of } \\
\text { chloroform to decane }\end{array}$ & $1: 90$ & $1: 120$ & $1: 150$ & $1: 400$ & $1: 1000$ & $1: 5000$ \\
\hline $\begin{array}{c}\text { Concentration of } \\
\text { chloroform (ppm) }\end{array}$ & 6945 & 5252 & 2367 & 1603 & 644 & 129 \\
\hline
\end{tabular}

\section{Calculation of SERS enhancement factor (EF)}

To quantify the enhancement contribution from $\mathrm{SiO}_{2}, \mathrm{SiO}_{2}-\mathrm{Ag}$ substrates, we calculated their enhancement factor (EF) based on the following formula:

$$
\mathrm{EF}=\left(\mathrm{I}_{\text {SERS }} / \mathrm{I}_{\mathrm{BULK}}\right) \times\left(\mathrm{N}_{\mathrm{BULK}} / \mathrm{N}_{\text {SERS }}\right)
$$

$\mathrm{N}_{\text {BULK }}=($ Laser spot area/Diffusion area $) *\left(N A *\right.$ Volume $_{\text {BULK }}{ }^{*}$ Concentration $\left.{ }_{\text {BULK }}\right)$

$\mathrm{N}_{\mathrm{SERS}}=($ Laser spot area/Substrate area $) *\left(\mathrm{NA} *\right.$ Volume $_{\text {SERS }}{ }^{*}$ Concentration SERS $)$

Diffusion area $=\pi(\mathrm{d} / 2)^{2}=0.5027 \mathrm{~cm}^{2}$

Substrate area $=0.16 \mathrm{~cm}^{2}$

Volume $_{\text {BULK }}=$ Volume $_{\text {SERS }}$

$\mathrm{I}=$ intensity of the $1174 \mathrm{~cm}^{-1}$ peak

Concentration $_{\text {BULK }}=$ Concentration $_{\text {SERS }}$

$\mathrm{N}_{\text {BULK }} / \mathrm{N}_{\text {SERS }}=(0.16 / 0.5027)=0.3183$

$\mathrm{I}_{\mathrm{BULK}}=1479.87 \mathrm{a}$.u.

I $_{\text {SERS,SiO2-Ag }}=6399.2$ a.u.

$\mathrm{I}_{\mathrm{SERS}, \mathrm{SiO} 2-\mathrm{Ag}} / \mathrm{I}_{\mathrm{BULK}}=4.32$

$\mathrm{EF}=\left(\mathrm{I}_{\mathrm{SERS}} / \mathrm{I}_{\mathrm{BULK}}\right) \times\left(\mathrm{N}_{\mathrm{BULK}} / \mathrm{N}_{\mathrm{SERS}}\right)=1.38$

$I_{S E R S, S i O 2}=2146.18$ a.u.

$\mathrm{I}_{\mathrm{SERS}, \mathrm{SiO} 2} / \mathrm{I}_{\mathrm{BULK}}=1.45$

$\mathrm{EF}=\left(\mathrm{I}_{\text {SERS }} / \mathrm{I}_{\mathrm{BULK}}\right) \times\left(\mathrm{N}_{\text {BULK }} / \mathrm{N}_{\mathrm{SERS}}\right)=0.46$ 


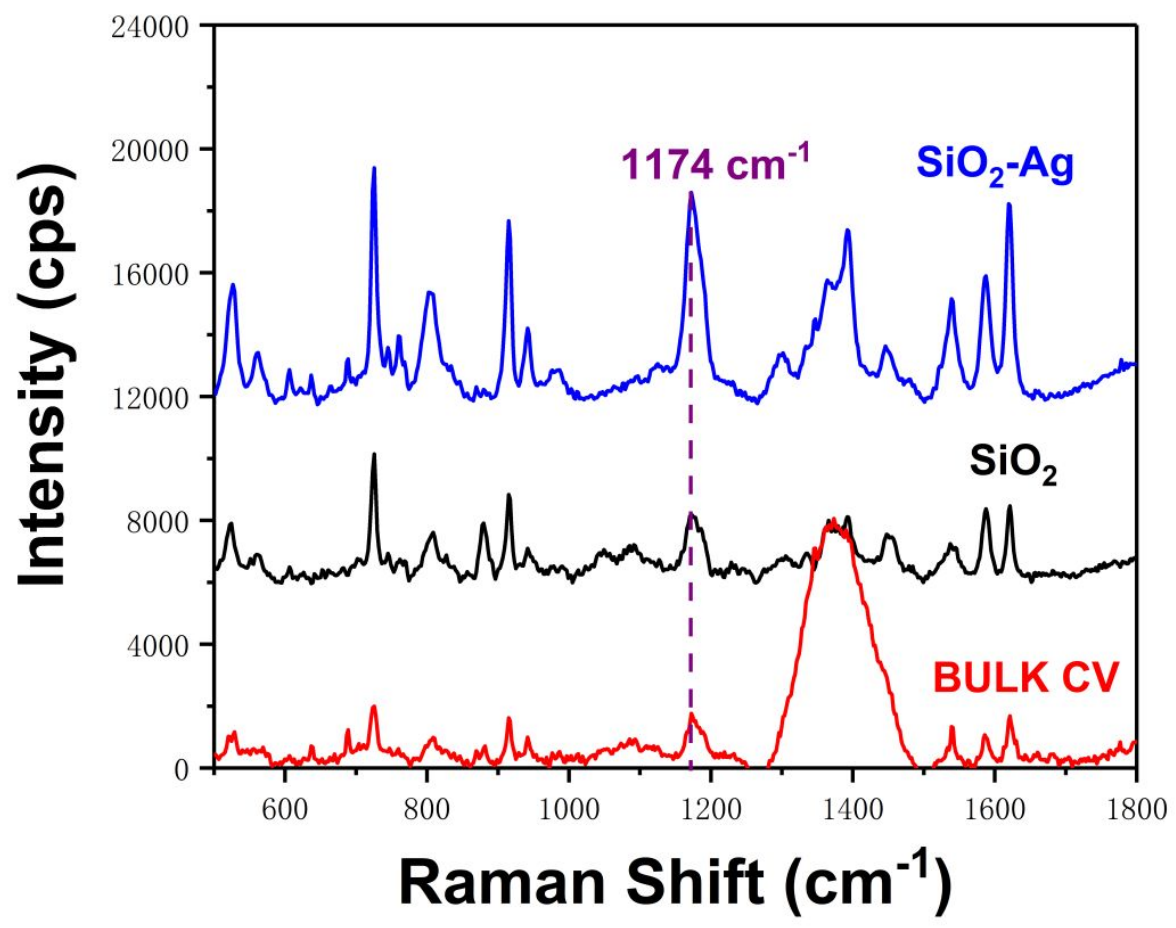

Figure S6. Raman spectrum of CV solution $\left(10^{-1} \mathrm{M}\right)$ and SERS spectra of $\mathrm{CV}\left(10^{-1} \mathrm{M}\right)$ absorbed on $\mathrm{SiO}_{2}$ substrate and $\mathrm{SiO}_{2}-\mathrm{Ag}$ substrate.

\section{Calculation of the limit of detection (LOD)}

The calculation of the limit of detection (LOD) was based on the standard deviation of the response and the slope of the curve,we calculated the limit of detection (LOD) based on the following formula:

$$
\mathrm{LOD}=3 \sigma / \mathrm{S}
$$

where $\sigma$ is the standard deviation of Raman intensity ( measurements of five replicates), and $S$ is the slope of the calibration curve (Figure 7).

For example, In an atmosphere of $68 \mathrm{ppm}$ toluene, the Raman intensity of peak at $1002 \mathrm{~cm}^{-1}$ was respectively $95.2,87.1,109.1,75.4,108.32$ a.u.

Standard deviation $=14.34$

$S=0.399$

$\mathrm{LOD}=3 \sigma / \mathrm{S}=107.8 \mathrm{ppm}$

Table S5. The limit of detection of Toluene, Benzene, Chloroform and Acetone. 


\begin{tabular}{|c|c|c|c|c|}
\hline Type of gas & Toluene & Benzene & Chloroform & Acetone \\
\hline $\begin{array}{c}\text { The limit of } \\
\text { detection }(\mathrm{ppm})\end{array}$ & 107.8 & 98 & 293.5 & 396.6 \\
\hline
\end{tabular}

